\title{
Gestão da educação básica e o fortalecimento dos Conselhos Escolares ${ }^{1}$
}

\section{Management of the basic education and the empowerment of the School Councils}

\author{
Márcia Angela da S. Aguiar*
}

\begin{abstract}
RESUMO
Examina-se a estratégia de implementação do Programa Nacional de Fortalecimento dos Conselhos Escolares adotada pela Secretaria de Educação Básica do Ministério da Educação com o objetivo de identificar os mecanismos utilizados para a inscrição da temática da gestão democrática na agenda das secretarias de educação e das escolas, bem como o envolvimento dos gestores e conselheiros escolares nos processos de formação promovidos pelo MEC, no período de 2004 a 2006.

Palavras-chave: Gestão da educação básica, conselhos escolares, democratização da gestão escolar, formação de conselheiros escolares, programa nacional de fortalecimento dos conselhos escolares.
\end{abstract}

\begin{abstract}
The strategy of implementation of the Programa Nacional de Fortalecimento dos Conselhos Escolares has been examined and adopted by the Secretary of Basic Education of the Department of Education (MEC) with the objective to identify the mechanisms used for the registration of the themes - democratic management - in the agenda of the secretaries of education and the schools, as per the involvement of the managers and the school council members in the processes of formation promoted by the MEC, during the period of 2004 to 2006 .
\end{abstract}

1 Este texto, com alterações, foi apresentado na mesa-redonda "A gestão das escolas entre as exigências políticas e os desafios pedagógicos" no IV Congresso Luso-Brasileiro de Política e Administração da Educação, na Faculdade de Psicologia e Ciências da Educação da Universidade de Lisboa, Portugal, em abril de 2007.

* Professora do Programa de Pós-Graduação em Educação da Universidade Federal de Pernambuco. 
Key words: Management of Basic Education, School Council, School Management democratization, School Council Members Formation, National Program for the Strengthening of School Councils.

\section{Introdução}

No contexto das lutas pela ampliação dos espaços de participação política, os setores organizados da população brasileira, em especial os educadores, têm desempenhado importante papel no sentido da democratização das políticas públicas de educação. Os esforços desses setores convergiram para o processo de definição da Constituição da República Federativa do Brasil (CF), de 1988, que incorporou, no artigo 206, a gestão democrática da educação como um de seus princípios basilares.

A Lei de Diretrizes e Bases da Educação Nacional (Lei n. 9493/1996)² ratifica os preceitos constitucionais e especifica, entre outros aspectos, os níveis e modalidades que compõem a educação nacional, a organização do sistema de ensino no país, as formas de financiamento e as competências dos entes federados - União, Estados e Municípios. Em seu artigo 14, estabelece que os sistemas de ensino definirão as normas da gestão democrática do ensino público na educação básica de acordo com as suas peculiaridades e conforme os seguintes princípios:

I - participação dos profissionais da educação na elaboração do projeto pedagógico da escola;

II - participação das comunidades escolar e local em conselhos escolares ou equivalentes.

A gestão democrática nas escolas públicas também constitui matéria do Plano Nacional de Educação (PNE), aprovado em janeiro de 2001, que dispõe, como uma de suas metas, a criação de conselhos escolares nos estabelecimentos oficiais que oferecem educação infantil, ensino fundamental e ensino médio.

Esse conjunto de leis estabelece as diretrizes e normas para a organização e gestão do sistema educacional brasileiro e orienta as ações, programas e políticas

${ }^{2} \mathrm{O}$ artigo 21 da LDBEN define que a educação escolar é composta pela educação básica (que abrange educação infantil, ensino fundamental, ensino médio e as modalidades da educação) e pela educação superior. 
que visam garantir o acesso, a permanência com qualidade, a gestão democrática e o financiamento da educação, em seus diferentes níveis e modalidades. Em cumprimento a esses dispositivos legais, os sucessivos governos, nas três esferas jurídico-administrativas (União, Estados e Municípios) têm conduzido políticas, programas e projetos relacionados à gestão da educação e incentivado o desenvolvimento de diferentes experiências pedagógicas e administrativas focalizando a gestão participativa nas escolas. Essas iniciativas, que ocorrem nas diversas esferas, encontram também amparo no artigo 211 da Constituição Federal, que dispõe que a União, os Estados, o Distrito Federal e os Municípios organizarão, em regime de colaboração, seus sistemas de ensino.

No presente texto, analisa-se a forma como parte dessas demandas da sociedade foram contempladas na primeira gestão do governo de Luiz Inácio Lula da Silva (2002-2006), observando-se a legislação educacional vigente. Privilegia-se a análise de um programa de grande envergadura - o Programa Nacional de Fortalecimento dos Conselhos Escolares, lançado no ano de 2004, pela Secretaria de Educação Básica do Ministério da Educação, tendo em vista que expressa uma linha de atuação política do governo federal com desdobramentos em todo o território nacional.

Para tanto, examina-se a estratégia de implementação do Programa, adotada pela instância ministerial com o objetivo de identificar os mecanismos utilizados para a inscrição da temática da gestão democrática na agenda das secretarias de educação e das escolas, bem como o envolvimento dos gestores e conselheiros escolares nos processos de formação promovidos pelo MEC, no período de 2004 a 2006. Problematizar os alcances e limites dessa política pública, à luz do debate sobre democratização e participação na gestão escolar, é o objetivo deste texto.

\section{Políticas para assegurar a gestão democrática: ainda um desafio}

O reconhecimento das reivindicações históricas do movimento dos educadores em prol da gestão democrática, bem como a necessidade de materializar no sistema educacional esse princípio preconizado pela LDBEN, constituíram algumas das fortes razões que induziram o Ministério da Educação a inscrever, na sua agenda, uma política direcionada à ampliação dos espaços de participação nas escolas de educação básica, o que se efetivou mediante a Portaria Ministerial n. 2.896/2004, que instituiu o Programa Nacional de Fortalecimento dos Conselhos Escolares. 
Este Programa, desenvolvido pela Secretaria de Educação Básica, foi concebido com o propósito de promover a cooperação do MEC com os sistemas estaduais e municipais de ensino, objetivando a implantação, consolidação e desempenho dos conselhos escolares nas escolas públicas de educação básica do país. Constituíram, assim, objetivos do Programa:

I - ampliar a participação das comunidades escolar e local na gestão administrativa, financeira e pedagógica das escolas públicas;

II - apoiar a implantação e o fortalecimento de Conselhos Escolares;

III - instituir políticas de indução para a implantação de Conselhos Escolares;

IV - promover, em parceria com os sistemas de ensino, a capacitação de conselheiros escolares, utilizando inclusive metodologias de educação à distância;

V - estimular a integração entre os Conselhos Escolares;

VI - apoiar os Conselhos Escolares na construção coletiva de um projeto educacional no âmbito da escola, em consonância com o processo de democratização da sociedade;

VII - promover a cultura do monitoramento e avaliação no âmbito das escolas para a garantia da qualidade da educação (Portaria Ministerial n. $2.896 / 2004$, art. $1^{\circ}$ ).

Com tais propósitos, o MEC, por meio da Secretaria de Educação Básica envolveu organismos e entidades nacionais e internacionais no processo de formulação dessa política, instituindo um grupo de trabalho interinstitucional com o objetivo de analisar e apresentar propostas que propiciassem o fortalecimento da gestão democrática e dos conselhos escolares nas escolas públicas de educação básica.

Integraram esse grupo de trabalho o Conselho Nacional de Secretários de Educação (Consed); a União Nacional dos Dirigentes Municipais de Educação (Undime); a Confederação Nacional dos Trabalhadores em Educação (CNTE); a Organização das Nações Unidas para a Infância (Unicef); a Organização das

${ }^{3}$ A Coordenação Geral de Articulação e Fortalecimento Institucional dos Sistemas de Ensino (CAFISE), do Departamento de Articulação e Desenvolvimento dos Sistemas de Ensino (DASE) foi a instância responsável pelo Programa Nacional de Fortalecimento dos Conselhos Escolares. 
Nações Unidas para a Educação, a Ciência e a Cultura (Unesco) e o Programa das Nações Unidas para o Desenvolvimento (Pnud). Simultaneamente, a SEB/ MEC buscou consultoria de especialistas na área de gestão da educação nas universidades brasileiras ${ }^{4}$ para colaborar com a arquitetura e operacionalização do Programa.

A SEB privilegiou, entre os objetivos do Programa, a promoção de parcerias com os sistemas de ensino, por intermédio das secretarias estaduais e municipais de educação, como a principal estratégia política, visando, de um lado, alcançar os demais objetivos e, de outro lado, induzir ações que reforçassem o regime de colaboração entre os entes federativos, tal como previsto na Lei de Diretrizes e Bases da Educação Nacional.

Ao atuar dessa forma, o governo federal procurava não só evidenciar uma postura favorável à afirmação do pacto federativo, mas, ao mesmo tempo, dar ampla visibilidade a uma ação político-pedagógica que poderia repercutir de forma positiva nas redes públicas de ensino diretamente envolvidas com esta ação.

Vale chamar a atenção para uma particularidade deste cenário: por se tratar de um programa de caráter pedagógico, as ações propostas não encontraram resistências da parte daquelas secretarias de educação de municípios e estados cujos titulares pertenciam a partidos políticos de oposição ao governo federal. Ao contrário, as manifestações de apoio das secretarias de educação à realização dos processos de formação de conselheiros escolares coordenados pelo MEC demonstram a ampla receptividade obtida pelo Programa. Em várias ocasiões, especialmente nas cerimônias de abertura dessas jornadas de formação, estiveram compartilhando o mesmo espaço representantes do governo federal e dirigentes e parlamentares de partidos opostos que, nos discursos, expressavam os mesmos argumentos em defesa de uma escola pública de qualidade. Esse fato pode ser explicado devido ao grande apelo que as bandeiras da qualidade de ensino e da participação da comunidade têm, tradicionalmente, no Brasil, mesmo naquelas situações em que a retórica predomina em detrimento de ações concretas.

A análise do Programa revela, também, dois aspectos que merecem destaque por traduzirem claramente a forma de fazer política do governo em tela: o processo de negociação entre o MEC e o grupo de trabalho instituído, e a proposta de formação dos conselheiros escolares. Verifica-se, em relação à formulação do Programa, que essas articulações foram conduzidas pela Secretaria

${ }^{4}$ Especialistas vinculados a várias universidades brasileiras, a saber: UFPE, UnB, UFG, UFSC, UFPb. 
de Educação Básica/MEC ${ }^{5}$ e envolveram instituições de natureza e interesses diferenciados, como anteriormente mencionado: a Undime, o Consed, a CNTE, a Unesco, a Unicef e o PNUD.

Com esses organismos e entidades, os dirigentes da SEB discutiram, em várias ocasiões, a pertinência e o formato do Programa, acertando-se uma proposta que teve a sua expressão legal na Portaria Ministerial n. 2.896/2004. Este grupo de trabalho também foi, posteriormente, convocado pela SEB para avaliar o conteúdo dos materiais que seriam utilizados no processo de formação dos conselheiros escolares.

Depreende-se, desse posicionamento, que o MEC teria a expectativa de que tal política, formulada em conjunto com esses parceiros, tivesse assegurada sua legitimidade junto aos sistemas de ensino, mesmo que formal e legalmente fosse sua prerrogativa exercer um papel indutor de políticas educacionais para todo o território nacional. Justifica-se, assim, o esforço feito pelos dirigentes da SEB no sentido de assegurar o apoio do Consed, da Undime e da CNTE à implementação do Programa nas redes públicas de ensino nos estados e territórios da federação.

No tocante ao processo de formação dos conselheiros escolares, para a sua estruturação, a SEB apoiou-se na equipe de especialistas na área de gestão da educação, vinculados às universidades, visando à formulação de uma proposta pedagógica que atendesse aos objetivos do Programa no sentido de estimular a gestão democrática nas escolas. A esses especialistas foi atribuída a responsabilidade de produzir o material pedagógico a ser utilizado nos processos de formação dos conselheiros escolares. É interessante ressaltar a centralidade que passou a ter a produção desse material, tendo em vista que a própria natureza dos conteúdos abordados determinou, em parte, a arquitetura do processo de formação, o que levou os gestores da SEB a valorizarem essa produção, considerada essencial para o sucesso do Programa.

Vale ressaltar, ainda, que o processo de produção do material pedagógico se estendeu por um período de um ano, concomitantemente ao período destinado à formação dos conselheiros escolares nos diversos estados. Nesse processo estiveram envolvidos, de forma diferenciada, os atores mencionados, o que gerou uma dinâmica que influenciou o próprio direcionamento do Programa. Em vez de agir como fazem usualmente as burocracias governamentais, definindo o produto esperado, o staff técnico responsável pela implementação das ações, na SEB/MEC, procurou participar ativamente de todas as etapas de

${ }^{5}$ Informações obtidas em entrevista com o coordenador da CAFISE/SEB/MEC, responsável pelas negociações iniciais do Programa Nacional de Fortalecimento dos Conselhos Escolares. 
elaboração do material pedagógico, junto com os especialistas das discussões teóricas e metodológicas concernentes ao Programa. Esse procedimento gerou uma dinâmica de interações entre os gestores do Programa e os especialistas que influenciou decisivamente o formato definido para o processo de formação dos conselheiros escolares.

A análise das dinâmicas atinentes à formulação e implementação do Programa mostra, sem dúvida, que

a construção das políticas públicas não é um processo abstrato. Ela é, ao contrário, indissociável da ação dos indivíduos ou dos grupos envolvidos, de sua capacidade de produzir discursos concorrentes, de seus modos de mobilização. Ela depende, também, de estrutura mais ou menos flutuante de suas relações e das estratégias elaboradas nos contextos de ação definidos em especial pelas estruturas institucionais, no interior das quais tomam lugar as políticas públicas (MULLER e SUREL, 2002, p.77).

Analisar a ação pública exige, portanto, que se leve em consideração os atores e as redes que são tecidas no espaço público.

\section{A gestão democrática e a formação dos conselheiros escolares}

Os gestores do Programa na Secretaria de Educação Básica do MEC, ao delinearem seus objetivos, requisitaram dos especialistas convidados que o material pedagógico a ser utilizado nos encontros de formação instigasse o debate sobre os conselhos escolares como um dos mecanismos de democratização da escola. Reconheciam, assim, a importância de possibilitar, aos diversos segmentos da escola, o acesso a um determinado tipo de material cujo conteúdo pedagógico favorecesse a reflexão e a discussão sobre a democracia, sobre os processos de participação e sobre a questão da cidadania. A expectativa era de que, com a divulgação desse material nas escolas, fosse ampliado o debate sobre os processos de gestão democrática, que não se restringiriam às eleições diretas para escolha do diretor.

Aliás, é importante registrar o fato de que a eleição direta para dirigentes das escolas de educação básica, no Brasil, constituiu uma bandeira dos movimentos dos educadores desde os anos de 1980, em prol da maior participação 
nas decisões no âmbito das escolas. Os estudos sobre o tema mostram que as análises que atribuíam à eleição direta do dirigente o condão de democratizar a escola foram substituídas por uma visão mais realista, que considera as eleições como um legítimo canal na democratização da escola e das relações mais amplas, mas sem perder de vista as limitações atinentes ao sistema representativo. Como afirma Dourado (2004), “a eleição, por si só, não é garantia da democratização da gestão"; é necessário "referendar essa modalidade de escolha como um importante instrumento, a ser associado a outros, para o exercício democrático" (2004, p. 38).

Os estudos nesse campo apontam para a necessidade da intensificação do debate sobre os processos de democratização e ampliação das instâncias e atores nos processos decisórios. Por sinal, dada a importância desse debate, o tema escolha do diretor integrou a pauta de um dos Cadernos Temáticos ${ }^{6}$ produzidos pelos especialistas.

Vale ressaltar que a equipe responsável pela produção desse material deparou-se com uma exigência específica: elaborar um material com consistência teórica e que fosse apresentado em linguagem coloquial e de fácil compreensão. Essa equipe enfrentou o desafio de tratar de temas complexos, tais como democracia e cidadania, sem proceder à redução dos conceitos, tampouco utilizando um padrão de linguagem que concorresse para a "infantilização" do conselheiro(a) escolar, como demonstra o tratamento dado aos textos dos Cadernos Temáticos analisados.

É importante assinalar que a metodologia utilizada na elaboração do material favoreceu a discussão entre a equipe de especialistas, a equipe técnica da SEB/MEC, gestores das secretarias de educação e conselheiros escolares sobre a pertinência, relevância e adequação dos temas tratados. Por fim, uma versão preliminar desse material veio à luz, na série de Cadernos Temáticos, assim especificados: 1. Conselhos Escolares: Democratização da escola e construção da cidadania; 2. Conselho Escolar e a aprendizagem na escola; 3. Conselho Escolar e o respeito e a valorização do saber e da cultura do estudante e da comunidade; 4. Conselho Escolar e o aproveitamento significativo do tempo pedagógico; 5. Conselho Escolar, gestão democrática da educação e escolha do diretor ${ }^{7}$.

A versão preliminar desses cadernos foi submetida à avaliação dos parceiros institucionais do MEC (Unesco, Unicef, Consed, Undime, CNTE) e a um grupo de 100 conselheiros escolares, em reuniões específicas. Embora os parceiros do MEC tenham acordado em apoiar a divulgação do material anali-

${ }^{6}$ Cf. DOURADO, Luiz F. et al.Caderno 5 - Conselho Escolar, gestão democrática da educação e escolha do diretor. Brasília: MEC/SE, 2004.

${ }^{7}$ Posteriormente foram elaborados pelos consultores mais cinco Cadernos Temáticos. 
sado, as discussões suscitadas na reunião de avaliação do material pedagógico evidenciaram diversas discordâncias de ordem política e pedagógica quanto ao conteúdo veiculado nos Cadernos. A aprovação sem restrições dos conteúdos veio, principalmente, do representante da Confederação Nacional dos Trabalhadores em Educação (CNTE), que, na ocasião, expressou o compromisso da entidade em buscar alternativas para garantir a divulgação do material em todas as escolas públicas do país.

De outro lado, foi ampla a receptividade que obteve o material pedagógico entre os conselheiros(as) escolares presentes no encontro de avaliação, os quais ao longo de dois dias, examinaram o conteúdo dos Cadernos Temáticos e deram contribuições significativas para o seu aperfeiçoamento, conforme demonstraram os resultados do instrumento de avaliação aplicado, nessa ocasião, pelos técnicos da SEB/MEC que acompanhavam o evento. Tal fato deu a legitimidade necessária ao material pedagógico e foi determinante para que a SEB autorizasse a sua impressão em larga escala e distribuição nos sistemas públicos de ensino.

Concluído o processo de elaboração dos Cadernos Temáticos, estes foram encaminhados pelo MEC às secretarias estaduais e municipais de educação e a todas as escolas públicas do Brasil com mais de 250 estudantes, juntamente com um caderno denominado Conselhos Escolares: Uma estratégia de gestão democrática da educação pública, destinado aos dirigentes e técnicos das secretarias municipais e estaduais de educação, e, ainda, um Caderno de Consulta intitulado Indicadores da Qualidade na Educação ${ }^{8}$, que visa ajudar a comunidade escolar na avaliação e na melhoria do trabalho pedagógico da escola. ${ }^{9}$

${ }^{8}$ Cf. Indicadores da qualidade na Educação. Ação Educativa, Unicef, Pnud, MEC (coords). São Paulo: Ação educativa, 2004. ISBN 85-86382-03.

${ }^{9}$ Posteriormente, em junho de 2006, por solicitação da SEB/MEC, foram elaborados mais cinco Cadernos que abrangem os seguintes temas: Caderno 6. Conselho Escolar como espaço de formação humana: círculo de cultura e qualidade da educação; Caderno 7. Conselho Escolar e o financiamento da educação no Brasil; Caderno 8. Conselho Escolar e a valorização dos trabalhadores em educação; Caderno 9. Conselho Escolar e a educação no campo; Caderno 10. Conselho Escolar e a relação entre a escola e o desenvolvimento com igualdade social. Disponível em: http:// portal.mec.gov.br/seb/index 


\section{O que dizem os Cadernos Temáticos sobre democracia, cidadania e gestão democrática da educação e da escola}

Visava-se, com os Cadernos Temáticos, estimular a reflexão e o debate sobre as potencialidades do conselho escolar como fator impulsionador de novas relações pedagógicas na escola. Os Cadernos concebiam os Conselhos Escolares como "órgãos colegiados compostos por representantes das comunidades escolar e local, com a atribuição específica de deliberar sobre questões político-pedagógicas, administrativas e financeiras, no âmbito da escola" ${ }^{10}$. Nesta ótica, situa-se na esfera de responsabilidade dos Conselhos a análise das ações a empreender e os meios a utilizar para materializar as finalidades da escola.

Ao considerar que os membros do Conselho Escolar representam as comunidades escolar e local, que atuam de forma coletiva e que definem estratégias para a tomada de decisões sobre temas de sua responsabilidade, o Programa demonstrava ter, como modelo, uma gestão escolar participativa. Nessa perspectiva, o Conselho Escolar seria o território que possibilitaria a "discussão, negociação e encaminhamento das demandas educacionais" favorecendo, desse modo, a participação social e a promoção da gestão democrática. Nessa direção, configura-se o Conselho Escolar como "uma instância de discussão, acompanhamento e deliberação, na qual se busca incentivar uma cultura democrática, substituindo a cultura patrimonialista pela cultura participativa e cidadã" (CADERNO 1, p. 33).

Essa concepção de conselho escolar, de caráter democrático, contrapõe-se à tradição patrimonialista do Estado brasileiro, que exibe relações sociais permeadas pelo clientelismo e pela política do favor. Nesse sentido, em um programa governamental para o setor de educação, definir rumos que se contrapõem à cultura tradicional significa entrar para o terreno da utopia. E é exatamente esse caráter utópico que emerge com maior ênfase, ao se efetivar uma análise de conteúdo dos textos dos Cadernos Temáticos. Predomina a idéia de construção de uma sociedade igualitária, que se pauta em relações democráticas e que respeita as diferenças.

Nessa ótica, considera-se que a escola pública tem um papel fundamental para a construção de uma cidadania participativa, esta entendida como construção permanente e coletiva. Nesse sentido, os Conselhos Escolares são considerados, primordialmente,

${ }^{10}$ Cf. Caderno 1- Conselhos Escolares: democratização da escola e construção da cidadania. 
o sustentáculo de projetos político-pedagógicos que permitam a definição dos rumos e das prioridades das escolas, numa perspectiva emancipadora, que realmente considere os interesses e as necessidades da maioria da sociedade. (CADERNO 1, p. 33)

Esse entendimento traz à cena o caráter atribuído ao projeto político -pedagógico da escola, visualizado na perspectiva das correntes progressistas que defendem a escola como espaço de formação cidadã. Assim, o projeto político-pedagógico constitui o referencial das ações da escola. Nos Cadernos Temáticos, esse projeto é concebido como

um processo que inclui as discussões sobre a comunidade local, as prioridades e os objetivos de cada escola e os problemas que precisam ser superados, por meio da criação de práticas pedagógicas coletivas e da co-responsabilidade de todos os membros da comunidade escolar. (CADERNO 1, p. 33)

Situar o projeto pedagógico nessa perspectiva significa considerar a escola como o espaço privilegiado de formação humana e socialização do saber sistematizado, entendendo que a construção desse saber pressupõe a participação de todos os sujeitos envolvidos no processo educativo, como condição básica para que a formação se concretize.

Essa visão traz várias implicações de ordem pedagógico-administrativa para as escolas, que precisam criar espaços e instituir mecanismos de participação de modo a tornar a gestão, de fato, democrática. Isso implica buscar meios para incentivar a participação da comunidade local e escolar na definição das prioridades e planejar as ações pedagógico-administrativas de forma colegiada.

Nessa linha, um dos Cadernos Temáticos ${ }^{11}$, ao se referir a essas ações, deixa claro que

11 Caderno 7 - Conselho Escolar e o financiamento da educação no Brasil. 
o planejamento participativo visa não só democratizar as decisões, mas fundamentalmente estabelecer o que é prioritário para os atores envolvidos e constitui-se um ato de cidadania, na medida em que esse processo possibilita a definição da concepção de homem, de educação e de mundo com os quais a escola deve trabalhar, de determinados programas e investimento e a avaliação das condições e conseqüências para a sua implementação. (CADERNO 7, p. 60)

Nesse contexto, a presença do Conselho Escolar é imprescindível, uma vez que, como instância colegiada, com a representação dos diversos segmentos da escola e da comunidade local, cabe-lhe coordenar e acompanhar as discussões concernentes às prioridades e objetivos da escola, analisar e encaminhar os problemas de ordem administrativa ou pedagógica, conhecer as demandas e potencialidades da comunidade local, estimular a instituição a práticas pedagógicas democráticas e transparentes, e incentivar a co-responsabilidade no desenvolvimento das ações de todos os que integram a comunidade escolar.

\section{Considerações finais}

O Programa Nacional de Fortalecimento dos Conselhos Escolares teve uma ampla abrangência ao envolver as secretarias de educação de estados e municípios nos processos formativos de conselheiros escolares. Sua implementação, conduzida pela SEB/MEC, em parceria com as secretarias de educação, foi marcada pela busca de coerência entre os objetivos delineados e as ações propostas, aspecto nem sempre observado em programas governamentais.

Com efeito, observa-se que, desde a sua formulação, que envolveu variados atores, as ações desenvolvidas pelo Programa visavam responder às demandas históricas dos movimentos sociais e dos educadores, em prol de uma efetiva gestão democrática das escolas, em especial no tocante à concepção de gestão participativa.

Pode-se entender, nesse sentido, de um lado, a ênfase dada, nos textos dos Cadernos Temáticos, aos temas que tratam das concepções de participação, democracia e cidadania relacionadas à construção do Projeto Político-Pedagógico da escola e, de outro a organização dos processos formativos dos conselheiros escolares, centrados nos conteúdos dos Cadernos e com a presença, como facilitadores desse processo, dos próprios autores do material pedagógico. 
Esse último aspecto foi sempre destacado nos discursos dos conselheiros(as) ao fazerem as avaliações dos processos formativos, tendo em vista o diálogo estabelecido, que possibilitou uma troca de saberes de fundamental importância para a compreensão da complexidade da relação entre os segmentos da escola e os representantes da comunidade local com as secretarias de educação e sindicatos de professores, em função dos interesses maiores da educação básica.

Um aspecto relevante desse Programa também pode ser identificado na estratégia de implementação adotada pela SEB/MEC de favorecer, simultaneamente, a atualização das equipes pedagógicas das secretarias de educação na temática da gestão democrática e a participação efetiva dos gestores das escolas e conselheiros escolares nos processos de formação. Com essa iniciativa, a SEB/MEC sinalizava para a importância das vivências coletivas no sentido de tornar possível a criação de colegiados interessados na construção de práticas pedagógicas refletidas no cotidiano da escola.

O caráter inovador do Programa pode ser constatado na dinâmica de sua formulação, que envolveu atores diferenciados da sociedade civil; na forma compartilhada como se processou a produção do material pedagógico; na escolha de aportes teóricos que contribuíssem para o fortalecimento e consolidação do projeto político-pedagógico da escola e, ainda, na estratégia de divulgação da proposta pedagógica nas redes públicas de ensino do país.

A demonstração dada pelos gestores da SEB/MEC de que o governo federal estava aberto ao debate sobre a ampliação da participação dos segmentos escolares e da comunidade nos processos decisórios da escola, tendo como finalidade última assegurar a qualidade social da educação, constituiu um passo importante para a inclusão ou ampliação desse debate no âmbito das secretarias de educação. Uma evidência desse fato pode ser vista na alta demanda pela aquisição dos Cadernos Temáticos, por parte de técnicos, gestores, docentes e conselheiros escolares dos estados e municípios, instituição de fóruns de conselhos escolares, solicitações dirigidas ao MEC para oferta de capacitações centradas na temática da gestão democrática entre outros.

Por fim, entende-se que o Programa favoreceu, no âmbito das redes públicas de ensino, a compreensão de que o Conselho Escolar pode ser construído de forma coletiva, como um lugar de participação e decisão de caráter pedagógico e político, como um espaço de debate e negociações em torno das necessidades e prioridades da escola e como um canal de democratização da gestão escolar.

Embora ainda não estejam disponíveis todos os dados que possam indicar com precisão a repercussão do Programa na totalidade das escolas envolvidas nos processos formativos, certamente a crescente organização de novos Conselhos Escolares e o movimento associativo que está emergindo entre essas instâncias, denominados Fóruns de Conselhos Escolares, em vários municípios, 
bem como os relatos de experiências inovadoras de constituição desses colegiados registrados no banco de experiências do site do Programa no portal do MEC, são indicadores que permitem considerar a relevância dessa ação pública para a ampliação da gestão democrática na escola pública, tendo como fulcro a qualidade da educação para a formação cidadã. Estudos e pesquisas sobre os desdobramentos do Programa na realidade das escolas públicas e o seu impacto na melhoria da educação básica trarão subsídios importantes para ampliar o conhecimento sobre os processos de democratização da escola e da sociedade brasileira, bem como sobre as políticas públicas de educação.

\section{REFERÊNCIAS}

AGUIAR. Márcia A.; SILVA, Aida M. M. (Org.). Retrato da escola no Brasil. Brasília: CNTE, 2004.

AGUIAR, Márcia A. et al. Conselho Escolar e o aproveitamento significativo do tempo pedagógico. Brasília: MEC/SEB, 2004.

AGUIAR, Márcia A. da S.; FERREIRA, Naura Syria C. (Org.). Gestão da educação: impasses, perspectivas e compromissos. São Paulo: Cortez, 2000.

AGUIAR, Márcia Angela da S. A formação do profissional da educação no contexto da reforma educacional brasileira. In: FERREIRA, Naura Syria C. (Org.). Supervisão educacional para uma escola de qualidade. São Paulo: Cortez, 1999.

. Espaço da gestão na formação do profissional da educação. In: FERREIRA, Naura Syria C.; MACHADO, Lourdes M. Política e gestão da educação: dois olhares. Rio de Janeiro: DP\&A, 2002. p. 107-122.

. A formação dos profissionais da educação básica no curso de Pedagogia. In: FERREIRA, N. S. C.; AGUIAR, M. A. da S. (Org.). Para onde vão a orientação e a supervisão educacional. 2. ed. Campinas: Papirus, 2002. p. 183-204.

ANTUNES, Ricardo. Reestruturação produtiva e mudanças no mundo do trabalho numa ordem neoliberal. In: DOURADO, Luiz F.; PARO, Vitor H. (Org.). Políticas públicas e educação básica. São Paulo: Xamã, 2001. p. 13-28.

ARRETCHE, M. Relações federativas nas políticas sociais. Educação \& Sociedade, Campinas, v. 23, n. 80, p. 25-48, set. 2002. 
AZEVEDO, Janete. Educação como política pública. São Paulo: Autores Associados, 1997. (Coleção Polêmicas do Nosso Tempo).

BENEVIDES, Maria Vitória. A cidadania ativa. São Paulo: Ática, 1996.

BOBBIO, Norberto. O futuro da democracia: uma defesa das regras do jogo. Rio de Janeiro: Paz e Terra, 2000.

BRASIL. Constituição da República Federativa do Brasil. Promulgada em $5 / 10 / 1998$.

BRASIL. Lei de Diretrizes e Bases da Educação Nacional: Lei n. 9394/1996. Disponível em: <www.mec.gov.br/lrgis/default.sthm>. Acesso em: 30/3/2006.

CATANI, Afrânio M.; GUTIERREZ, Gustavo L. Participação e gestão escolar: conceitos e potencialidades. In: FERREIRA, Naura C. Gestão democrática da educação: atuais tendências, novos desafios. São Paulo: Cortez, 2001. p. 59-75.

CASTEL, R. As metamorfoses da questão social: uma crônica da questão social. Petrópolis: Vozes, 1999.

CURY, Carlos Roberto Jamil. O público e o privado no Brasil: fronteiras e perspectivas. In: FERREIRA, Naura Syria C. (Org.). Gestão democrática da educação: atuais tendências, novos desafios. São Paulo: Cortez, 1998.

. O público e privado no Brasil: fronteiras e perspectivas In: OLIVEIRA, Dalila Andrade; DUARTE, Marisa R. (Org.). Política e trabalho na escola: administração dos sistemas públicos de educação básica. Belo Horizonte: Autêntica, 1999. p. 123-128.

DALE, R. Globalização e educação: demonstrando a existência de uma cultura educacional comum ou localizando uma agenda globalmente estruturada para a educação. Educação, Sociedade \& Culturas, Porto, n. 16, p. 133-169, 2001.

DOURADO, Luiz F. A escolha de dirigentes escolares: políticas e gestão da educação no Brasil. In: FERREIRA, Naura C. Gestão democrática da educação: atuais tendências, novos desafios. São Paulo: Cortez, 2001. p. 77-96.

DOURADO, Luiz F. et al. Conselho Escolar, gestão democrática da educação e escolha do diretor. Brasília: MEC/SEB, 2004.

DOURADO, Luiz F. et al. Conselhos Escolares e o financiamento da educação no Brasil. Brasília: MEC/SEB, 2006.

GRACINDO, Regina Vinhaes. Projeto político-pedagógico: retrato da escola em movimento. In: AGUIAR. Márcia A; SILVA, Aida M. M. (Org.). Retrato da escola no Brasil. Brasília: CNTE, 2004. p. 161-176. 
GRACINDO, Regina V. et al. Conselho Escolar a aprendizagem na escola. Brasília: MEC/SEB, 2004.

NAVARRO, Ignez Pinto et al. Conselhos Escolares: democratização da escola e construção da cidadania. Brasília: MEC/SEB, 2004.

OLIVEIRA, Dalila; DUARTE, Marisa. Politica e trabalho na escola: administração de sistemas públicos de educação básica. Belo Horizonte: Autêntica, 1999.

OLIVEIRA, Romualdo P. Reformas educativas no Brasil na década de 90. In: CATANI, A; OLIVEIRA, R. P. Reformas educativas no Brasil e em Portugal. Belo Horizonte: Autêntica, 2000. p. 77-94.

PARO, Vitor Henrique. Gestão democrática da escola pública. São Paulo: Ática, 1997.

RODRIGUES, Neidson. Por uma nova escola: o transitório e o permanente na educação. São Paulo: Cortez/Autores Associados, 1986.

VEIGA, Ilma P. A.; RESENDE, Lúcia M. G. de (Org.). Escola: espaço do projeto político-pedagógico. Campinas: Papirus, 1998.

Texto recebido em 24 ago. 2007 Texto aprovado em 27 out. 2007 